RESEARCH REPORT

\title{
Risk of breast cancer after miscarriage or induced abortion: a Scottish record linkage case-control study
}

\author{
David H Brewster, Diane L Stockton, Richard Dobbie, Diana Bull, Valerie Beral
}

J Epidemiol Community Health 2005;59:283-287. doi: 10.1136/jech.2004.026393

See end of article for authors' affiliations

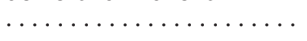

Correspondence to: Dr D H Brewster,

Information Services, NHS National Services Scotland, Gyle Square, 1 South Gyle Crescent, Edinburgh EH12 9EB, UK; david.brewster@isd.csa. scot.nhs.uk

Accepted for publication 10 September 2004

\begin{abstract}
Study objective: To assess the risk of breast cancer in patients with a previous history of miscarriage or induced abortion.

Design: Case-control study relating "exposure" to outcome by linkage of national hospital discharge and maternity records, the national cancer registry, and death records.

Setting: Scotland.

Participants: Miscarriage analysis - 2828 women with breast cancer and 9781 matched controls; induced abortion analysis -2833 women with breast cancer and 9888 matched controls.

Main results: After stratification for age at diagnosis, parity, and age at first birth, the odds ratio $195 \%$ confidence intervals) of breast cancer was 1.02 (0.88 to 1.18) in women with a previous miscarriage, and $0.80(0.72$ to 0.89$)$ in women with a previous induced abortion. Further adjustments for age at bilateral oophorectomy, socioeconomic status (based on small area of residence), and health board area of residence had only minor effects on these odds ratios.

Conclusion: These data do not support the hypothesis that miscarriage or induced abortion represent substantive risk factors for the future development of breast cancer.
\end{abstract}

C hildbearing has been consistently shown to reduce the risk of breast cancer in the long term. ${ }^{1}$ Until recently, incomplete pregnancies were thought to have no effect, or perhaps slightly reduce the risk of breast cancer. ${ }^{2}$ However, in 1990, Remennick carried out a literature review and suggested that induced abortion might increase the risk of breast cancer. ${ }^{3}$ Brind came to similar conclusions in 1996, ${ }^{4}$ although others who reviewed the evidence came to different conclusions. $^{5-7}$ Although some have quoted animal evidence ${ }^{8}$ to support the view that induced abortion might increase the risk of breast cancer, it is difficult to know the relevance of these findings for humans.

To investigate the potential role of miscarriage and induced abortion as risk factors for the future development of breast cancer, the Collaborative Group on Hormonal Factors in Breast Cancer collated and analysed data on individual women from 53 studies undertaken in 16 countries. ${ }^{9}$ Among 44000 women with prospectively recorded information on miscarriage or induced abortion (that is, information that had been recorded before the diagnosis of breast cancer), the group found that there was no evidence of an increased risk of breast cancer. However, this study did not investigate the risk of breast cancer in subgroups of women, stratified by factors such as week of gestation or maternal age at miscarriage or induced abortion.

This paper reports the results of a study designed to assess the risk of breast cancer in patients with a previous history of miscarriage or induced abortion, using computerised NHS records collated routinely in Scotland, which has a limited private healthcare sector, especially relating to obstetrics and oncology. Although these data had not been published previously, they were included in the meta-analysis referred to above. However, for reasons of space, it was only possible to provide limited details of study design, methods, and results in the ensuing publication. ${ }^{9}$ In this paper, we provide further details of study design, methods, results of subgroup analyses, and some consideration of the study's strengths and limitations.

\section{METHODS}

From the linked database of acute hospital discharge (SMR01) records, cancer registrations, and death records in Scotland, "cases" were identified and "controls" selected from the period spanning 1981-1998. Cases were defined as women with new incident breast cancers diagnosed before 55 years of age (most older women are unlikely to have been exposed to miscarriage or induced abortion in the time frame of this study). Controls were defined as women without cancer admitted to acute hospitals for any non-obstetric, non-gynaecological conditions and were matched for year of admission for breast cancer (corresponding to the date of the case's breast cancer diagnosis), year of birth, health board of residence, and 1991 census based Carstairs' deprivation quintile, the last two based on postcode sector of residence at the time of hospital admission (corresponding to the case's breast cancer diagnosis). The Carstairs deprivation score is a small area indicator of socioeconomic status based on the prevalence measured at the decennial census of four characteristics: overcrowding, male unemployment, social class, and car ownership. ${ }^{11}$ Although based on small area of residence rather than individual characteristics, it can be used to show clearly the lower risk of breast cancer among women from more deprived communities. ${ }^{12}$ Cases and controls were excluded if they had any history of cancer (other than non-melanoma skin cancer) or carcinoma in situ of breast before the date of diagnosis of breast cancer/ hospital admission. All potentially eligible matched controls were identified and up to four per case were selected randomly.

Using computerised probability matching ${ }^{10}$ and with the approval of the Privacy Advisory Committee that advises the NHS Information Services in Scotland, all acute hospital discharge (SMR01), cancer registration, and death records for each case and control were linked to their corresponding records on the linked maternity (SMR02) database (spanning 1980 onwards) to generate an anonymised dataset for analysis. It is estimated that this method of linkage results 
Table 1 Number of cases and controls in the miscarriage analysis

\begin{tabular}{llrlr}
\hline Miscarriage & Cases & \multicolumn{1}{l}{$\%$} & Controls & \multicolumn{1}{l}{$\%$} \\
\hline No & 2575 & 91.1 & 8873 & 90.7 \\
Yes & 253 & 9.0 & 908 & 9.3 \\
Total & 2828 & 100.0 & 9781 & 100.0 \\
\hline
\end{tabular}

in mismatched records in less than $2 \%$ of cases. ${ }^{10}$ The following information was extracted for each case and control: nature and date of each reproductive event; gestational age of any miscarried or aborted fetus; history of bilateral oophorectomy; cancer diagnoses and dates; date and causes of death; and hospital admissions.

Although the variables were available for 1981 onwards, the maternity database included the number of previous reproductive events for each woman, based on a combination of self reporting, general practitioner referral letter, and available medical records, so that it was possible to identify women for whom their whole reproductive history was known. The following women were eligible for inclusion in the study:

- those with all reproductive events occurring from 1981 onwards

- those with some reproductive events occurring before 1981, and number of pregnancies equalled number of births-that is, no miscarriages or induced abortions before 1981 (note that the age at first birth was unknown for this group).

\section{Statistical analysis}

Odds ratios (OR) of breast cancer and 95\% confidence intervals (95\% CI), according to miscarriage/induced abortion history, were calculated using conditional logistic regression stratifying for age at diagnosis rather than preserving the individual matching, to increase efficiency. Separate models were applied to each subgroup analysis. The analyses were repeated using individually matched sets (also conditional logistic regression) and the results did not deviate from those presented here (data not shown). All the statistical analyses were conducted using Stata (version 8.2, StataCorp, 19852003).

\section{RESULTS}

\section{Miscarriage}

This analysis included 2828 cases and 9781 controls whose reproductive history of miscarriage was known. The average year of breast cancer diagnosis was 1994; of these women a similar proportion ( $9 \%$ ) had a history of miscarriage (table 1).

After stratifying for age at diagnosis and the potential confounding factors, parity $(0,1-2,3-4,5-6,7+$ births $)$ and age at delivery of first child $(12-19,20-24,25-29,30+$, unknown age, no children), the odds ratio of breast cancer was 1.02 in women with a previous miscarriage compared with women with no history of miscarriage (95\% CI: 0.88 to $1.18 ; \mathrm{p}=0.8$ ).

Age at delivery of first child was unknown (as before 1981) for $61 \%$ of cases and $58 \%$ of controls. When women with unknown age at delivery of first child were excluded from the analyses, the odds ratio was little changed (OR $=0.96$; $95 \%$ CI: 0.72 to $1.30 ; p=0.8$ ) compared with the overall odds ratio of 1.02 .

Table 2 Adjusted* odds ratios of breast cancer for women who have had a pregnancy ending in miscarriage compared with women with no pregnancy ending in miscarriage

\begin{tabular}{|c|c|c|c|}
\hline Subgroup & Number of women & Odds ratio $(95 \% \mathrm{Cl})$ & $\mathrm{p}$ Value \\
\hline No miscarriage & 11448 & 1.00 & \\
\hline Miscarriage & 1161 & 1.02 (0.88 to 1.18$)$ & 0.81 \\
\hline \multicolumn{4}{|l|}{$\begin{array}{l}\text { Week of gestation (of earliest } \\
\text { miscarriage) }\end{array}$} \\
\hline No miscarriage & 11448 & 1.00 & \\
\hline$<9$ weeks & 192 & $1.10(0.78$ to 1.55$)$ & 0.61 \\
\hline $9-10$ weeks & 178 & $0.81(0.55$ to 1.19$)$ & 0.29 \\
\hline $11-12$ weeks & 162 & 0.89 (0.60 to 1.32$)$ & 0.55 \\
\hline$>12$ weeks & 205 & $0.90(0.63$ to 1.27$)$ & 0.55 \\
\hline Unknown & 424 & $1.20(0.96$ to 1.51$)$ & 0.12 \\
\hline \multicolumn{4}{|l|}{ Age at miscarriage } \\
\hline No miscarriage & 11448 & 1.00 & \\
\hline $12-19$ years & 17 & $1.34(0.43$ to 4.18$)$ & 0.61 \\
\hline $20-24$ years & 134 & 0.65 (0.38 to 1.09$)$ & 0.10 \\
\hline $25-29$ years & 278 & $0.96(0.71$ to 1.29$)$ & 0.77 \\
\hline $30+$ years & 732 & $1.10(0.92$ to 1.32$)$ & 0.29 \\
\hline \multicolumn{4}{|l|}{ Number of miscarriages } \\
\hline 0 & 11448 & 1.00 & \\
\hline 1 & 1031 & 1.01 (0.86 to 1.18 ) & 0.91 \\
\hline 2 & 110 & $1.19(0.76$ to 1.87$)$ & 0.44 \\
\hline $3+$ & 20 & $0.67(0.20$ to 2.32$)$ & 0.53 \\
\hline \multicolumn{4}{|l|}{ Time since miscarriage } \\
\hline No miscarriage & 11448 & 1.00 & \\
\hline$<1$ year & 51 & $1.16(0.6$ to 2.23$)$ & 0.66 \\
\hline $1-4$ years & 253 & 1.21 (0.9 to 1.62$)$ & 0.22 \\
\hline $5-9$ years & 377 & 1.05 (0.82 to 1.35$)$ & 0.70 \\
\hline $10+$ years & 480 & $0.89(0.71$ to 1.12$)$ & 0.33 \\
\hline \multicolumn{4}{|l|}{ Temporal sequencet‡ } \\
\hline No miscarriage & 11448 & 1.00 & \\
\hline Miscarriage while nulliparous & 207 & 1.08 (0.78 to 1.49$)$ & 0.66 \\
\hline Live birth then miscarriage & 537 & 0.79 (0.64 to 0.99$)$ & 0.04 \\
\hline Unknown sequence§ & 417 & 1.11 (0.88 to 1.39$)$ & 0.37 \\
\hline
\end{tabular}


Table 3 Number of cases and controls in the induced abortion analysis

\begin{tabular}{lllll}
\hline $\begin{array}{l}\text { Induced } \\
\text { abortion }\end{array}$ & Cases & $\%$ & Controls & $\%$ \\
\hline No & 2322 & 82.0 & 7651 & 77.4 \\
Yes & 511 & 18.0 & 2237 & 22.6 \\
Total & 2833 & 100.0 & 9888 & 100.0 \\
\hline
\end{tabular}

Of the initial cohort of women whose reproductive history of miscarriage was known, $2.55 \%$ had a bilateral oophorectomy before the breast cancer diagnosis/control's hospital admission date. Adjustment in turn for potential confounding factors including age at bilateral oophorectomy (never, $<40,40-44,45-49,50+$ ), and the initial matching variables, deprivation category and health board of residence, had only a minor effect on the odds ratio $(\mathrm{OR}=1.02, \mathrm{OR}=1.01$ and $\mathrm{OR}=1.05$, respectively).

There were no clear or significant effects when investigating breast cancer risk in relation to week of gestation of miscarriage, age at miscarriage, number of miscarriages, or time since miscarriage (table 2). However, the risk of breast cancer seemed to be lower than expected for women who had a live birth followed by a miscarriage (OR $=0.79$; 95\% CI: 0.64 to $0.99 ; \mathrm{p}=0.04$ ) compared with women who had no history of miscarriage.

\section{Induced abortion}

This analysis included 2833 cases and 9888 controls whose reproductive history of induced abortion was known. The average year of breast cancer diagnosis was 1994; of these women $18 \%$ of cases and $23 \%$ of controls had a history of induced abortion (table 3).

After stratifying for age at diagnosis, parity, and age at delivery of first child, the odds ratio of breast cancer was 0.80 in women with a previous induced abortion compared with women with no history of induced abortion (95\% CI: 0.72 to $0.89 ; \mathrm{p}<0.001$ ).

Age at delivery of first child was unknown (as before 1981) for $61 \%$ of cases and $58 \%$ of controls. When women with unknown age at delivery of first child were excluded from the analyses, the odds ratio was reduced further $(\mathrm{OR}=0.73$; CI: 0.57 to $0.93 ; \mathrm{p}=0.01$ ).

Of the initial cohort of women whose reproductive history of induced abortion was known, $2.5 \%$ had a bilateral oophorectomy before the breast cancer diagnosis/control's hospital admission date. Adjustment in turn for age at bilateral oophorectomy, deprivation category, and health board of residence, had only a minor effect on the odds ratio $(\mathrm{OR}=0.79, \mathrm{OR}=0.79$, and $\mathrm{OR}=0.82$, respectively $)$.

There were no clear effects when investigating breast cancer risk in relation to week of gestation of induced abortion, age at induced abortion, number of induced abortions, time since induced abortion, or the temporal sequence of live births and induced abortions (table 4).

\section{DISCUSSION}

The results of our study do not support the hypothesis that prior miscarriage or induced abortion represent significant risk factors for later development of breast cancer. Historically, much of the epidemiological data relating to the potential association between induced abortion and

Table 4 Adjusted* odds ratio of breast cancer for women who have had a pregnancy ending in induced abortion compared with women with no pregnancy ending in induced abortion

\begin{tabular}{|c|c|c|c|}
\hline Subgroup & Number of women & Odds ratio $(95 \% \mathrm{Cl})$ & p Value \\
\hline No abortion & 9973 & 1.00 & \\
\hline Abortion & 2748 & $0.80(0.72$ to 0.89$)$ & $<0.001$ \\
\hline \multicolumn{4}{|c|}{ Week of gestation (of earliest abortion) } \\
\hline No abortion & 9973 & 1.00 & \\
\hline$<9$ weeks & 203 & $0.65(0.44$ to 0.97$)$ & 0.03 \\
\hline 9-10 weeks & 194 & 0.93 (0.65 to 1.33$)$ & 0.69 \\
\hline $11-12$ weeks & 63 & $0.87(0.46$ to 1.65$)$ & 0.67 \\
\hline$>12$ weeks & 119 & $0.35(0.19$ to 0.66$)$ & $<0.01$ \\
\hline Unknown & 2169 & $0.83(0.73$ to 0.93$)$ & $<0.01$ \\
\hline \multicolumn{4}{|l|}{ Age at abortion } \\
\hline No abortion & 9973 & 1.00 & \\
\hline $12-19$ years & 98 & 1.08 (0.64 to 1.83$)$ & 0.76 \\
\hline $20-24$ years & 311 & $0.67(0.48$ to 0.95$)$ & 0.02 \\
\hline $25-29$ years & 487 & $0.84(0.66$ to 1.07$)$ & 0.15 \\
\hline $30+$ years & 1852 & $0.80(0.70$ to 0.91$)$ & $<0.01$ \\
\hline \multicolumn{4}{|l|}{ Number of abortions } \\
\hline 0 & 9973 & 1.00 & \\
\hline 1 & 2383 & $0.82(0.73$ to 0.93$)$ & $<0.01$ \\
\hline 2 & 302 & $0.62(0.45$ to 0.86$)$ & $<0.01$ \\
\hline $3+$ & 63 & $0.74(0.37$ to 1.48$)$ & 0.40 \\
\hline \multicolumn{4}{|l|}{ Time since abortion } \\
\hline No abortion & 9973 & 1.00 & \\
\hline$<1$ year & 105 & $0.64(0.37$ to 1.09$)$ & 0.10 \\
\hline $1-4$ years & 608 & 0.85 (0.69 to 1.05$)$ & 0.14 \\
\hline $5-9$ years & 953 & $0.83(0.70$ to 0.99$)$ & 0.04 \\
\hline $10+$ years & 1082 & $0.75(0.64$ to 0.89$)$ & $<0.001$ \\
\hline \multicolumn{4}{|l|}{ Temporal sequencet‡ } \\
\hline No abortion & 9973 & 1.00 & \\
\hline Abortion while nulliparous & 155 & $0.77(0.51$ to 1.15$)$ & 0.20 \\
\hline Live birth then abortion & 876 & $0.72(0.60$ to 0.86$)$ & $<0.001$ \\
\hline Unknown sequence§ & 1717 & $0.75(0.66$ to 0.85$)$ & $<0.001$ \\
\hline
\end{tabular}

*Adjusted for age, parity, and age at delivery of first child. †No information on miscarriages/induced abortions before 1981. ‡Adjusted for age only (as includes nulliparous women). §"Unknown" includes women who have had an induced abortion since 1981 (and no live births since 1981) but whose maternal history sequence before 1981 is unknown. 


\section{Key points}

- Although miscarriage is generally not considered to be a risk factor for the subsequent development of breast cancer, there is less consensus about the possible role of induced abortion.

- The risk of breast cancer in patients with a previous history of miscarriage or induced abortion was investigated in a hospital based record linkage casecontrol study in Scotland.

- The results of this study do not support the hypothesis that miscarriage or induced abortion represent substantive risk factors for the future development of breast cancer.

breast cancer has been generated from case-control interview studies. An important issue is whether such studies are subject to reporting bias as far as a history of induced abortion is concerned. ${ }^{13-19}$ Studies based on linkage of independent records are not subject to this potential source of bias and, with one exception, ${ }^{20}$ have not found a statistically significant increase in risk of breast cancer after induced abortion. ${ }^{21-24}$ This underlines the importance of assigning exposure (to induced abortion) status based on information recorded before the diagnosis of breast cancer. Our results are also consistent with the recently published meta-analysis by the Collaborative Group on Hormonal Factors in Breast Cancer. ${ }^{9}$ Although our data were included in this meta-analysis, it is evident that their exclusion would not change the overall conclusion that miscarriage or induced abortion do not seem to increase the risk of subsequent breast cancer. A more recent prospective study in AfricanAmerican women also found that induced abortion did not increase the risk of subsequent breast cancer. ${ }^{25}$

The main strengths of our study are the size and national coverage of the study population, the objective recording of prior induced abortion status, the matching of controls for variables such as year of birth, place of residence, and socioeconomic status, and the availability of information on the important potential confounding variables, parity, and age at delivery of first child. However, the study is based on computerised health records collected routinely to serve many purposes, but not specifically for the purpose of this study. While this does not necessarily invalidate the use of the data for this study, it does mean that there are potential weaknesses inherent to the study design that must be acknowledged.

The important weakness of the study relates to missing data on miscarriage and induced abortion status and potential confounding factors for a substantial proportion of the original potential study population. Women with no reproductive history, or all of their reproductive history occurring before 1981, were not eligible for inclusion in the study. However, the percentages of women who had to be excluded from the study on this basis were similar between cases $(79 \%)$ and controls $(80 \%)$. As the information available to us was derived from inpatient and day-case hospital records, the study is not strictly population based, and we did not have access to information about recognised or unrecognised miscarriages managed entirely outside hospital (unless this became incorporated in the history fields of maternity records). This may explain the lower than expected percentage of women with a recorded history of miscarriage. In contrast, the data on induced abortion seem likely to be reasonably complete. Based on statutory returns for the year 2001 , less than $4 \%$ of abortions induced in Scottish residents took place outside NHS hospitals in Scotland (Chalmers J, personal communication). Overall, we think that differential misclassification of miscarriage, induced abortion, and reproductive history is unlikely to be present to any significant extent among the study populations included in each analysis. Indeed, if our finding of no association between miscarriage and subsequent breast cancer is valid, it is difficult to think of a credible, systematic bias that would apply exclusively to our other analysis and conceal a positive association between induced abortion and subsequent breast cancer.

While we did find an apparently reduced risk of breast cancer among women who had a live birth followed by a miscarriage, it is difficult to think of a satisfactory explanation, and it could represent a chance finding in the context of multiple tests of statistical significance. Similarly, although our results actually suggest a possible protective effect of induced abortion, this finding might be explained by incomplete information on confounding factors, and is not supported by our subgroup analyses in which we found no clear trends in risk. Of particular interest, we did not find evidence of an increased risk of breast cancer among women having abortions induced after 12 weeks gestation, in contrast with Melbye et al who, in their Danish record linkage cohort study, observed a statistically significant increase in risk among women undergoing induced abortion after 18 weeks gestation, admittedly based on a comparatively small number of cases in this subgroup. ${ }^{23}$

In summary, like almost every epidemiological study, our study does have strengths and weaknesses, and it would be unwise to draw conclusions based on the data from this one alone. However, the data we have analysed and presented do not support the hypothesis that miscarriage or induced abortion represent substantive risk factors for the future development of breast cancer.

\section{ACKNOWLEDGEMENTS}

We are grateful to Dr Jim Chalmers for advice about the Scottish (SMR02) maternity database and comments on the manuscript, and to Anne Stott for providing data.

\section{Authors' affiliations}

D H Brewster, D L Stockton, R Dobbie, Information Services, NHS National Services Scotland, Edinburgh, UK

D Bull, V Beral, Cancer Research UK Epidemiology Unit, The Raddliffe Infirmary, Oxford, UK

Funding: none.

Conflicts of interest: none declared.

\section{REFERENCES}

1 Collaborative Group on Hormonal Factors in Breast Cancer. Breast cancer and breastfeeding: collaborative reanalysis of individual data from 47 epidemiological studies in 30 countries, including 50302 women with breast cancer and 96973 women without the disease. Lancet 2002;360:187-95.

2 Vessey MP, McPherson K, Yeates D, et al. Oral contraceptive use and abortion before first term pregnancy in relation to breast cancer risk. Br J Cancer 1982;45:327-31.

3 Remennick LI. Induced abortion as cancer risk factor: a review of epidemiological evidence. J Epidemiol Community Health 1990;44:259-64.

4 Brind J, Chinchilli VM, Severs WB, et al. Induced abortion as an independent risk factor for breast cancer: a comprehensive review and meta-analysis. $J$ Epidemiol Community Health 1996;50:481-96.

5 Michels KB, Willett WC. Does induced or spontaneous abortion affect the risk of breast cancer? Epidemiology 1996;7:521-8.

6 Wingo PA, Newsome K, Marks JS, et al. The risk of breast cancer following spontaneous or induced abortion. Cancer Causes Control 1997;8:93-108.

7 Bartholomew LL, Grimes DA. The alleged association between induced abortion and risk of breast cancer: biology or bias? Obstet Gynecol Surv 1998;53:708-14.

8 Russo J, Russo IH. Susceptibility of the mammary gland to carcinogenesis. II. Pregnancy interruption as a risk factor in tumor incidence. Am J Pathol 1980;100:497-512.

9 Collaborative Group on Hormonal Factors in Breast Cancer. Breast cancer and abortion: collaborative reanalysis of data from 53 epidemiological 
studies, including 83000 women with breast cancer from 16 countries. Lancet 2004;363:1007-16

10 Kendrick S, Clarke J. The Scottish Record Linkage System. Health Bull (Edinb) 1993:51:72-9.

11 Morris R, Carstairs V. Which deprivation? A comparison of selected deprivation indexes. J Public Health Med 1991;13:318-26.

12 Scottish Cancer Intelligence Unit. Trends in Cancer Survival in Scotland, 1971-1995. Edinburgh: Information and Statistics Division, 2000:98.

13 Rookus MA. Reporting bias in case-control studies on induced abortion and breast cancer. Am J Epidemiol 2000;151:1144-7.

14 Tang MT, Weiss NS, Daling JR, et al. Case-control differences in the reliability of reporting a history of induced abortion. Am J Epidemiol 2000;151:1139-43.

15 Brind J, Chinchilli VM, Severs WB, et al. Induced abortion and risk for breast cancer: reporting (recall) bias in a Dutch case-control study. (Letter). J Natl Cancer Inst 1997;89:588-90.

16 Rookus MA, van Leeuwen FE. Induced abortion and risk for breast cancer: reporting (recall) bias in a Dutch case-control study. J Natl Cancer Inst 1996:88: 1759-64.

17 Weed DL, Kramer BS. Induced abortion, bias, and breast cancer: why epidemiology hasn't reached its limit. J Natl Cancer Inst 1996;88: 1698-700.
18 Newcomb PA, Storer BE, Longnecker MP, et al. Pregnancy termination in relation to risk of breast cancer. JAMA 1996;275:283-7.

19 Lindefors-Harris BM, Eklund G, Adami HO, et al. Response bias in a case-control study: analysis utilizing comparative data concerning legal abortions from two independent Swedish studies. Am J Epidemiol 1991;134:1003-8.

20 Howe HL, Senie RT, Bzduch H, et al. Early abortion and breast cancer among women under Age 40. Int J Epidemiol 1989;18:300-4.

21 Goldacre MJ, Kurina LM, Seagroatt V, et al. Abortion and breast cancer: a case-control record linkage study. J Epidemiol Community Health 2001;55:336-7.

22 Lazovich D, Thompson JA, Mink PJ, et al. Induced abortion and breast cancer risk. Epidemiol 2000;11:76-80.

23 Melbye M, Wohlfahrt J, Olsen $\mathrm{JH}$, et al. Induced abortion and the risk of breast cancer. N Engl J Med 1997;336:81-5.

24 Lindefors-Harris B-M, Eklund G, Meirik O, et al. Risk of cancer of the breast after legal abortion during first trimester: a Swedish register study. BMJ 1989;299:1430-2.

25 Palmer JR, Wise LA, Adams-Campbell $L$, et al. A prospective study of induced abortion and breast cancer in African-American women. Cancer Causes Control 2004;15:105-11. 